Research Article

\title{
Experimental Research on Performance of New Gas Drainage Borehole Sealing Material with High Fluidity
}

\author{
Xin Guo $\mathbb{D}$, Sheng Xue, Chunshan Zheng $\mathbb{D}$, and Yaobin Li $\mathbb{i}^{\circ}$ \\ School of Safety Science and Engineering, Anhui University of Science \& Technology, Huainan, Anhui 232001, China \\ Correspondence should be addressed to Xin Guo; guoxin190510@163.com
}

Received 8 December 2020; Revised 15 January 2021; Accepted 28 January 2021; Published 9 February 2021

Academic Editor: Hongchao Kou

Copyright ( $) 2021$ Xin Guo et al. This is an open access article distributed under the Creative Commons Attribution License, which permits unrestricted use, distribution, and reproduction in any medium, provided the original work is properly cited.

\begin{abstract}
To ensure the sealing effect of gas extraction borehole in underground coal mine and improve the concentration of gas extraction, a kind of high-flow sealing material which can be injected into the microcracks around borehole was developed. The ultrafine cement as the base material, with water-reducing agent, expansion agent, retarder, the material, and water combined stir, will form a kind of colloid with high fluidity and slightly expansibility. This paper analyzes the differences between the new high-fluidity sealing material and ordinary cement materials in expansion performance, compressive strength, and sealing performance. Scanning electron microscope and mercury intrusion method were used to analyze the differences in microscopic morphology and pore structure of these two materials. The experimental results show that the new high-fluidity sealing material has an excellent fluidity of $295.5 \mathrm{~mm}$ with an expansion rate of $60 \mathrm{~d}$ being $1.562 \%$. The new high-fluidity sealing material is convenient for grouting with strong material permeability and superior sealing performance. Field test results show that the effect of the new high-fluidity sealing material is better than the ordinary cement materials. The average drainage concentration and flux during the drainage period were $59.07 \%$ and $0.243 \mathrm{~m}^{3} / \mathrm{min}$, respectively, which showed that the drainage efficiency was significantly improved. This novel sealing material is of great significance for improving the efficiency of drilling and drainage.
\end{abstract}

\section{Introduction}

Gas extraction is the most effective method of controlling gas in coal mines [1], whose effect is determined by the quality of sealing material. The common traditional sealing materials of mines in China cement and polyurethanes have many disadvantages. The poor adhesion of cement to coal shrinks and cracks will result in low construction efficiency. Polyurethane sealing material is expensive and toxic.

Lots of experts have conducted modified research on sealing materials. Cao et al. $[2,3]$ studied the influence of PVA fiber and steel fiber content on the rheological properties of cement mortar. The study concluded that when the content of PVA fiber is $0.25 \%$, the impact on the flow properties of cement mortar is small; when the content of steel fiber is less than $0.75 \%$, the fluidity of cement mortar can be enhanced. When the content of steel fiber is increased to $1.00 \%$, the fluidity of cement mortar will decrease. Zhai et al. [4-6] have developed a new type of sealing material by adding water-retaining agents, expansion agents, and other materials to fly ash, and the material has good fluidity and expansion. Wang et al. [7] have developed a DE secondary expansion material with a strong time effect by adding expansion agents, water reducers, and other additives to cement. Miao et al. [8] studied the influence of the content and fineness of limestone powder on the rheological properties of cement paste: the fluidity of cement slurry increases with the increase in the content of limestone powder, and decreased with the increase of limestone powder fineness. Zhang et al. $[9,10]$ have prepared coal/ polymer composite grouting material with improved mechanical properties by adding binders to coal chips. Du et al. [11] have conducted an orthogonal liquidity test on viscosity-varying grouting materials with different pumping time; the influence of water-cement ratio and the additive agent on the properties of slurry flow are analyzed. Kazuki et al. [12] studied the influence of the molecular structure of superplasticizers on the fluidity of cement slurry sealing 
materials. The study showed that the smaller molecular structure helps the dispersion of cement particles and improves the flow of cement slurry sealing materials. Güllü et al. [13] have developed a grouting material with improved fluidity using fly ash and cold-bonded fly ash. Wang et al. [14] have studied the fluidity of glass fiber cement paste and found that mixing glass fiber with pure cement paste would reduce the fluidity of pure cement paste, and the higher the glass fiber content, the more obvious the effect. Wang et al. [15] have developed nanoscale cement materials with delayed setting time and improved fluidity. Kamalakannan et al. [16] have studied the density, setting time, mechanical strength, and other parameters of several common cement grout. Bi et al. [17] have studied the influence of the type and content of calcium sulfate on the hydration mechanism of gas drainage borehole sealing materials and found that the use of sealing materials with low calcium sulfate content is beneficial to the hydration reaction. Wongkornchaowalit and Lertchirakarn [18] studied the influence of polycarboxylic acid superplasticizer on the fluidity of Portland cement. The research results proved that when the polycarboxylic acid superplasticizer was $1.8 \%-2.4 \%$, the fluidity of cement has increased substantially.

At present, traditional sealing materials are not effective for microcrack grouting, shrink, and crack easily and have poor durability. In response to these shortcomings, in this paper, a high-fluidity and environment-friendly sealing material with high injectability, controllable setting time, high strength, stable volume, and proper density with minerals was prepared to overcome the poor grouting effect on microcracks of traditional sealing materials. By combining the comparison between the high-fluidity sealing material and the ordinary cement sealing material in terms of macro characteristics, microstructure and pore structure, and the results of the sealability experiment, it can be seen that the new high-fluidity sealing material is better, which proves the necessity of promoting new high-fluidity sealing material.

\section{Materials and Methods}

After the sealing materials with high-fluidity properties being poured into the fine cracks of coal and rock mass and the slurry reaching the sealing section, a certain degree of swelling and strength was required to consolidate, fill, and seal the fine cracks of the coal and rock mass timely and effectively. Moreover, the period in which the grout maintains a high-fluidity state cannot be too short. Otherwise, the operation time will be too short, which is inconducive to the grouting construction. The period cannot be too long, either. Otherwise, the spreading range of the grout will be challenging to control, and the grouting project will not be effective and timely [19]. A sealing material with high fluidity was designed by adjusting the amount of added admixtures according to the actual needs of sealing and the characteristics of ultrafine cement.

The primary raw material of the new high-fluidity sealing material is ultrafine cement, to which expansion agent, water reducer, and retarder were added. The appearance of ultrafine Portland cement is gray with the measured values of D90 and D 50 being $12.6 \mu \mathrm{m}$ and $5 \mu \mathrm{m}$, respectively, which can effectively be injected into microcracks below $0.1 \mathrm{~mm}$ [20]. The expansion agent is a calcium oxide-calcium sulfate compound expansion agent (HCSA) with a gray-white appearance, which is conducive to the formation of an excellent spatial structure of cement hydration products and the improvement of the expansion rate [21-23]. The polycarboxylic acid water-reducing agent (PCE) with water reduction rate being $20-35 \%$ that is a white powder easily soluble in water is used to disperse cement particles, improve the fluidity of cement, and reduce unit water consumption $[24,25]$. The retarder used is white seaweed powder, easily soluble in water, and can improve the setting time and strength of cement materials [26].

The composition of the new high-fluidity sealing material was finally determined with single-factor and orthogonal experiments to meet the performance requirements of strength, expansion, fluidity, and so on. The mass ratio of the components was ultrafine cement: retarder: water-reducing agent: expansion agent $=100$ : $0.03: 0.5: 8$. The water-cement ratio was $1: 1$. The new highfluidity sealing material produced after mixing is shown in Figure 1 . The ordinary cement used in the comparison experiment was the P.O32.5 ordinary Portland cement produced by the Bagongshan Cement Plant.

\section{Material Performance Test}

3.1. Fluidity Test. The determination method of cement mortar fluidity (GB/T2419-2005) was adopted. The wellmixed cement slurry was poured into the round mold, which was quickly lifted after the surface being scraped. The round mold is $60 \mathrm{~mm}$ in height with an upper mouth diameter of $36 \mathrm{~mm}$ and a lower mouth diameter of $60 \mathrm{~mm}$. After the flow of the cement slurry, the two diameters perpendicular to each other were measured, the average value of which was used as the fluidity (Figure 2). According to the measured data, when the water-cement ratio was $1: 1$, the fluidity of the new high-flow sealing material was $295.5 \mathrm{~mm}$, and the fluidity of ordinary cement was $268 \mathrm{~mm}$, indicating that the modification of ultrafine cement significantly improved the fluidity of cement slurry.

3.2. Microstructure Test. The micromorphology of ordinary cement materials and new high-fluidity sealing materials in different curing periods were observed in high vacuum mode using FEI Quanta 200 FEG environmental scanning electron microscope (SEM) (Figure 3). The working principle of SEM is to scan the sample with a very thin electron beam, which excites secondary electrons on the surface of the sample. The secondary electrons are collected by the detector and converted into light signals by the scintillator there and then pass through the photomultiplier tube and The amplifier converts into an electric signal to control the intensity of the electron beam on the phosphor screen and displays a scanned image synchronized with the electron beam. The image is a three-dimensional image, reflecting the 


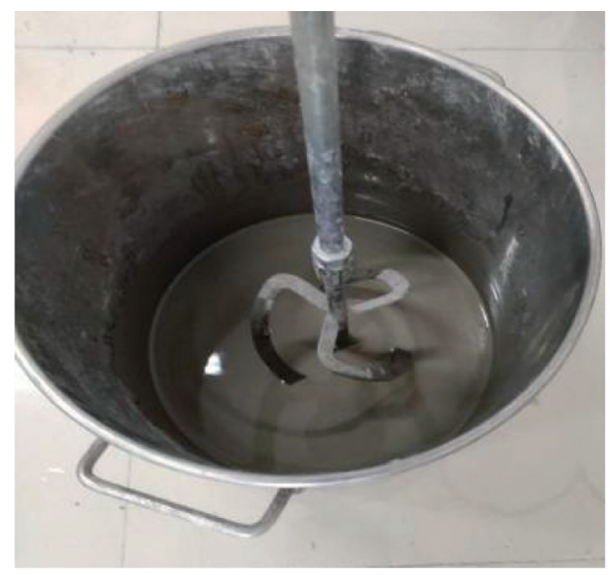

Figure 1: Mixed sealing material.
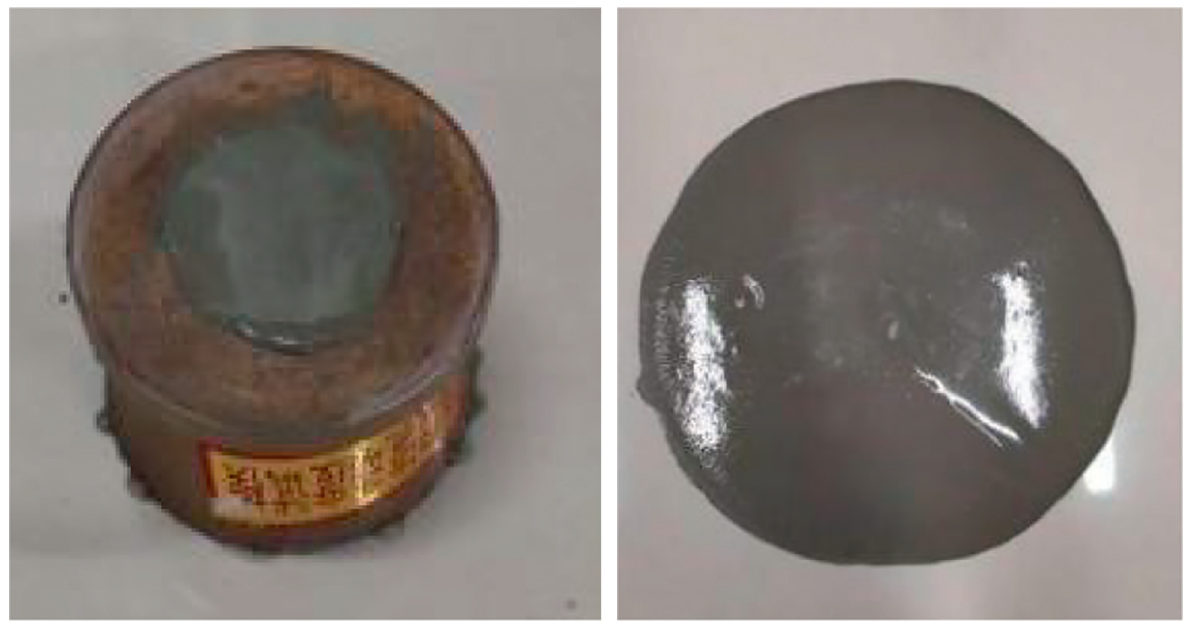

FIgURE 2: The test of material fluidity.

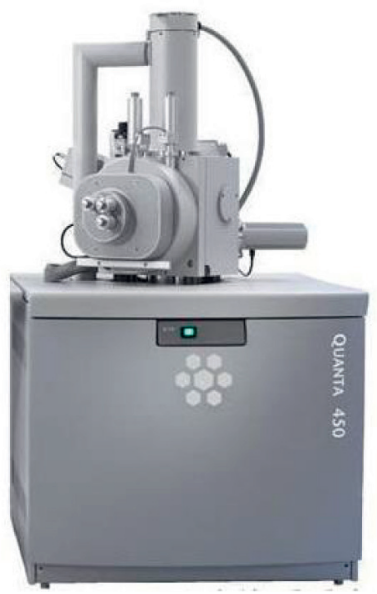

FIGURE 3: FEI Quanta 200 FEG environmental electronic scanning electron microscopy.

surface structure of the specimen. In order to make the surface of the specimen emit secondary electrons, after the specimen is fixed and dehydrated, a layer of heavy metal particles should be sprayed. The heavy metal emits secondary electron signals under the bombardment of the electron beam.

Mercury injection is an important method to analyze the pore structure. The AutoPore IV 9500 mercury porosimeter was adopted to measure total pore volume and porosity (Figure 4). The energy required to increase mercury into the solid by pressurizing the pore volume into the solid is equal to the work done by the external force, which is equal to the surface free energy under the mercury-solid interface under the same thermodynamic conditions. Using the cylindrical pore model, calculate the pore volume and specific surface area according to the relationship between pressure and capacitance, and calculate the pore size distribution according to the Huaxibao equation.

3.3. Expansion Test. Make cement slurry according to the water-cement ratio of $1: 1$. The mixture was poured into the three-way test mold $(70.7 \mathrm{~mm} \times 70.7 \mathrm{~mm} \times 70.7 \mathrm{~mm})$, which was then put into the curing box for curing (temperature $20 \pm 2^{\circ} \mathrm{C}$, relative humidity above $\left.95 \%\right)$. After molding and demolding, the initial volume of the test block was recorded as $V_{1}$, and the test block was kept in the curing box until the corresponding age was reached. The volume was recorded as 


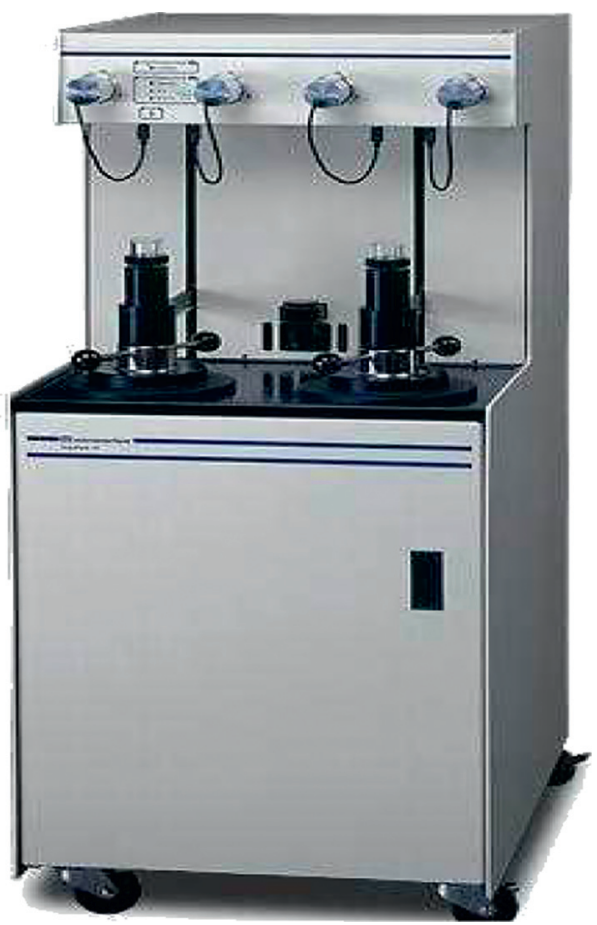

FIgURE 4: AutoPore IV 9500 mercury compressor.

$V_{n}$, and the expansion rate of the test block was calculated with the following formula:

$$
\varepsilon_{t}=\frac{V_{n}-V_{1}}{V_{1}} \times 100 \%,
$$

where $V_{n}$ is the volume of the specimen at a certain age and $V_{1}$ is the initial volume of the specimen.

3.4. Compressive Strength Test. The compressive strength of stones at different ages was measured with the RMT uniaxial press (Figure 5) according to GB/T50080-2016. The specific experimental steps are as follows:

(1) The test piece should be tested in time after it is taken out from the curing site, and the surface of the test piece and the upper and lower bearing plates should be wiped clean.

(2) Place the test piece on the lower plate or backing plate of the testing machine, and the pressure-bearing surface of the test piece should be perpendicular to the top surface during forming. The center of the test piece should be aligned with the center of the lower pressing plate of the testing machine. Start the testing machine. When the upper pressing plate is close to the test piece or the steel backing plate, adjust the ball seat to balance the contact.

(3) During the test, the load shall be applied continuously and evenly, and the concrete strength level shall be as follows: when $<\mathrm{C} 30$, the loading speed is 0.3 to $0.5 \mathrm{MPa}$ per second; when the concrete strength grade is $\mathrm{C} 30$ and $<\mathrm{C} 60$, it is $0.5-0.8 \mathrm{MPa}$ per second; when the concrete strength grade is $>-\mathrm{C} 60$, it is $0.8-1.0 \mathrm{MPa}$ per second.
(4) When the test piece is close to failure and begins to deform rapidly, stop adjusting the throttle of the testing machine until it fails. Then record the failure load.

3.5. Sealability Test. A box $(1.2 \mathrm{~m} \times 0.9 \mathrm{~m} \times 1.0 \mathrm{~m})$ was designed to test the tightness of the two materials. In the tightness test, similar materials (gypsum powder, coal powder, and sand) were put into the box to simulate the underground coal seam. The ground stress load is loaded into the equipment by the stress loading system. The equipment mainly includes a reaction plate located above the box, a support frame composed of four cylindrical screws, and a hydraulic jack as shown in Figure 6(a). After compacting the material, remove the steel plate on the side of the box (Figure 6(b)), and dig out two holes with a diameter of $100 \mathrm{~mm}$ and a length of $1 \mathrm{~m}$ (Figure 6(c)). Put two rigid PVC pipes with a diameter of $75 \mathrm{~mm}$ and a length of $0.5 \mathrm{~m}$ into the drilled hole. The length of the front end of the air chamber is $0.5 \mathrm{~m}$. Both ends of the pipe are sealed with Malisan, forming a sealed part in the middle (Figure 6(d)). When Malisan expands, new high-fluidity sealing material and ordinary cement sealing material are injected into the sealing part separately. After the material is cured, use an air pump to inject air into the pressure measurement chamber until the maximum pressure is reached, and then record the pressure drop. The initial pressure of the air chamber was $80 \mathrm{kPa}$, which was recorded at 20 minutes.

\section{Results and Discussion}

4.1. Fluidity Test. According to the measured data, when the water-cement ratio is $1: 1$, the fluidity of the new highfluidity sealing material is $295.5 \mathrm{~mm}$, while the fluidity of ordinary cement is $268 \mathrm{~mm}$. Due to the high density of carboxyl groups in the main chain of PCE, it is beneficial to adsorb on the surface of cement particles, generate electrostatic repulsion, and continuously disintegrate cement particle flocculation groups. Moreover, the long side chains form a steric hindrance effect, which will also decompose the cohesive structure of adjacent cement particles and improve the fluidity of the material [27].

4.2. Microscopic Characteristics Test. It can be seen from Figure 7 that the hydration products of ordinary cement materials during the curing period are with a loose structure and large pores, causing the low compressive strength of the material. After curing for three days, the cement clinker was wrapped by C-S-H gel, the hydrate with an apparent pore structure, and a large pore volume. After curing for 28 days, the C-S-H gels became the main products as the surface area and volume gradually increased. Besides, $\mathrm{CH}$ was formed, and the pore in the hydrate was less and smaller. After curing for 60 days, the number of C-S-H gels continued to increase, and high-density C-S-H gels were formed. With the advancement of the hydration reaction, the amount of C-S-H gel increased, and some needle-shaped AFt crystals appeared. 


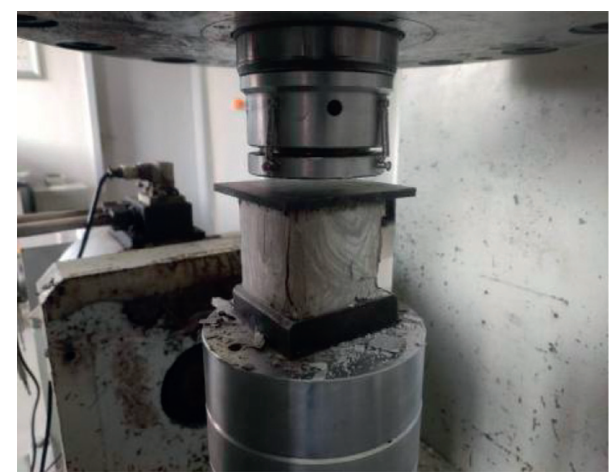

Figure 5: Compressive strength test.

It can be seen from Figure 8 that the gel particles of the new high-fluidity sealing material were interwoven into a single piece with a compact structure, improving the strength of the material. After curing for three days, C-S-H gels formed by hydration were wrapped in cement clinker, and $\mathrm{CH}$, a dense structure with few pores, was formed. After curing for 28 days, a large number of ettringite crystals were formed. Pores are filled with fine acicular ettringite, indicating that the addition of admixture contributes to cement hydration reaction and the formation of AFt crystal with expansion effect. The microstructure is more compact, and the strength was improved effectively. After curing for 60 days, AFm and $\mathrm{CH}$ were formed. The number of C-S-H gels increase, and $\mathrm{C}-\mathrm{S}-\mathrm{H}$ gels were uniformly cross-bonded with the gelling substances such as AFt generated in the early stage, improving the uniformity and compactness of the material and thereby enhancing the strength of the material [28].

The pore structures of the two materials were tested by mercury injection in the laboratory. According to the results of the mercury injection test, the porosity of ordinary cement material was $41.9128 \%$, and the average pore diameter was $40.44 \mathrm{~nm}$. The total mercury intake was $0.3316 \mathrm{~mL} / \mathrm{g}$, and the total pore specific surface area was $32.798 \mathrm{~m}^{2} / \mathrm{g}$. The porosity of the new high-fluidity sealing material decreased to $36.5285 \%$, and the average pore diameter decreased to $23.08 \mathrm{~nm}$. The total mercury intake decreased to $0.2987 \mathrm{~mL} /$ $\mathrm{g}$, and the total pore specific surface area increased to $51.766 \mathrm{~m}^{2} / \mathrm{g}$.

4.2.1. Pore Size Distribution Curve. Figure clearly illustrates the difference in pore size distribution between the pore diameter and mercury intake of samples of ordinary cement materials and new materials [29] (Figure 9). According to Hodot's pore classification method, the pores with diameters less than $0.01 \mu \mathrm{m}$ are defined as micropores. The pores with diameters of $0.01 \sim 0.1 \mu \mathrm{m}$ are defined as the transition pore. The pores with diameters of $0.1 \sim 1.0 \mu \mathrm{m}$ are defined as the mesopore. The pores with diameters of $1.0 \sim 100 \mu \mathrm{m}$ are defined as macropores. It can be seen from Figure 10 that the pores of the new high-fluidity sealing material distribute more concentratedly than those of the ordinary cement sealing material and most of the pores are micropores. The pore diameter of ordinary cement material is higher at the range of $0.05-0.1 \mu \mathrm{m}$. When the pore diameter was around $1 \mu \mathrm{m}$, the amount of mercury injected into the pore showed a second peak, indicating that the common cement pore sealing materials were mainly composed of micropores, transition pores, and mesopores. The pore diameter of the new high-fluidity sealing material has a higher range of $0.005-0.05 \mu \mathrm{m}$, indicating that the new high-fluidity sealing materials were mainly composed of micropores and transition pores.

4.2.2. Mercury Advance-Retreat Curve. The mercury advance-retreat curve can directly reflect the pore structure of different material samples $[30,31]$. The mercury intake of ordinary cement sealing materials can reach 1.11 times that of the new high-fluidity sealing materials, as shown in Figure 10. It can be seen from the curve morphology that the new high-fluidity sealing material has a higher volume of mercury in the micropores and ordinary cement sealing material has a higher amount of mercury in micropores, transition pores, and mesopores. Since mercury intake essentially reflects pore volume, the pore space of common cement pore sealing materials is more developed than that of new high-fluidity sealing materials.

4.3. Expansion Test. As shown in Figure 11, the changes in the expansion rate can be divided into three stages. In the first 14 days, the expansion rate of the new high-fluidity sealing material as well as the ordinary cement increases from $0.213 \%$ to $1.238 \%$ and decreases from $-0.233 \%$ in $1 \mathrm{~d}$ to $-0.619 \%$, respectively. From $14 \mathrm{~d}$ to $28 \mathrm{~d}$, the expansion rate of the two materials gradually slows down with the expansion rate of the new high-fluidity sealing material increasing from $1.238 \%$ to $1.532 \%$ and the expansion rate of ordinary cement decreasing from $-0.619 \%$ to $-0.793 \%$. From $28 \mathrm{~d}$ to $60 \mathrm{~d}$, the expansion rate of the two materials reaches a stable state with the expansion rate of the new high-fluidity sealing material increasing from $1.532 \%$ to $1.562 \%$ and the expansion rate of ordinary cement decreasing from $-0.793 \%$ to $-0.813 \%$. When the water cement is relatively large, the HCSA interacts with cement in the early hydration stage and produces many expansion products such as AFt with ideal expansion effects. From the SEM results of 4.2.1, it can be seen that the internal pores of ordinary cement materials are large, and ettringite crystals are mixed in the pores, which contributes little to the expansion of hardened slurry. The structure of the new highfluidity sealing materials is compact, and there are more ettringite crystals, water-absorbing expansion of which significantly contributes to the expansion of the material [32].

4.4. Compressive Strength Test. The compressive strength changes of the two materials are shown in Figure 12. It can be seen that the compressive strength increases with the curing period. In the early stage of curing, the strength of the two materials is quite different. When cured for three days, 


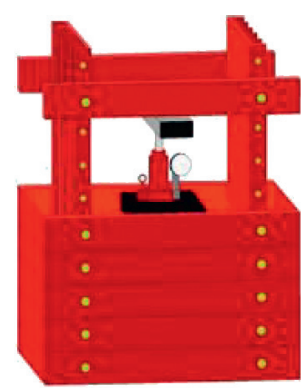

(a)

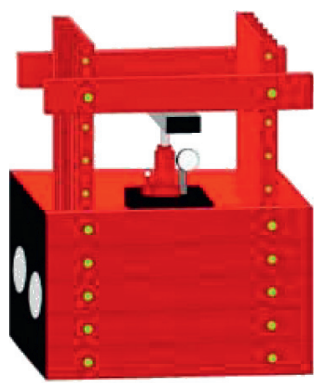

(c)

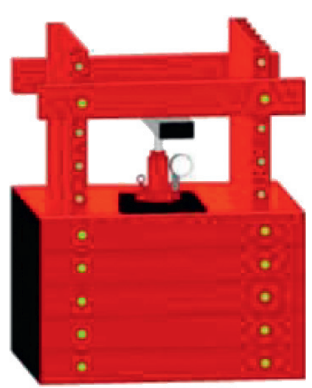

(b)

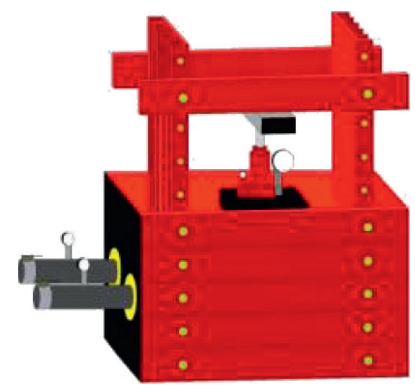

(d)

Figure 6: Test procedure of material sealing performance.

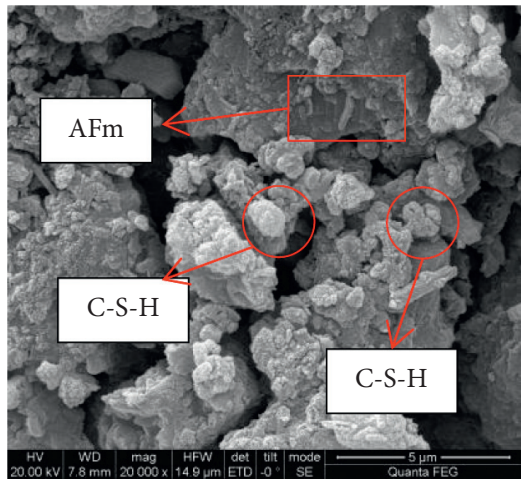

(a)

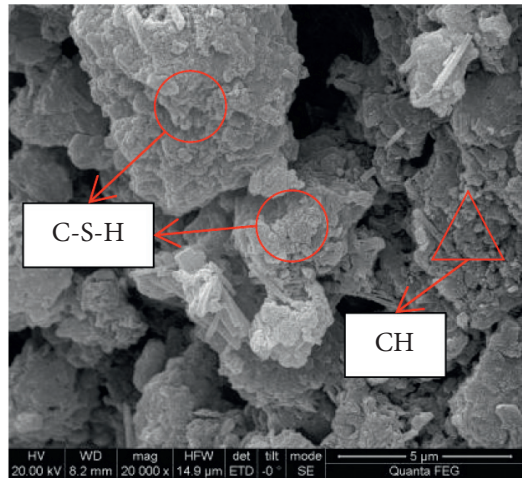

(b)

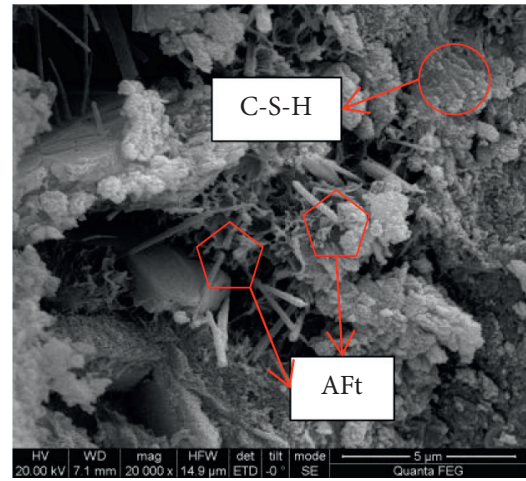

(c)

FiguRE 7: The micromorphology of ordinary cement materials at different curing ages. (a) Curing for three days, (b) curing for seven days, and (c) curing for sixty days.

the compressive strength of the two materials is $24.377 \mathrm{MPa}$ and $28.511 \mathrm{MPa}$, respectively. When cured for seven days, the compressive strength of the two materials is $29.013 \mathrm{MPa}$ and $32.026 \mathrm{MPa}$, respectively. When the curing period is 28 days, the compressive strength of the two materials is 38.785 $\mathrm{MPa}$ and $40.213 \mathrm{MPa}$, respectively.

According to the SEM results in 4.2.1, the hydration product of the new high-fluidity sealing material has smaller pores and a tighter structure. Therefore, the compressive strength of the new high-fluidity sealing material is more remarkable. According to the pore size distribution curve in 4.2.2, the pore size distribution of ordinary cement materials is in the range of $0.05-0.1 \mu \mathrm{m}$, while the pore size distribution of the new high-fluidity sealing material is in the range of $0.005-0.05 \mu \mathrm{m}$. According to research [32], the pore size less than $0.02 \mu \mathrm{m}$ has little effect on the strength of the material; therefore, reducing the pore size of the material will help improve the mechanical strength of the material.

4.5. Sealing Test. The better the sealing performance of the sealing material, the slower the pressure drop of the gas chamber. It can be seen from Figure 13 that, during the experiment, the average pressure of the gas chamber sealed with ordinary cement sealing material was $43 \mathrm{kPa}$. After closing the valve for 20 minutes, the gas chamber pressure began to drop. During the whole experiment, the pressure of the gas chamber dropped quickly, and the slope of the curve was large. After closing the valve for 300 minutes, the pressure of the gas chamber dropped to $0 \mathrm{kPa}$. The average pressure of the gas chamber sealed with the new high-fluidity sealing material was 


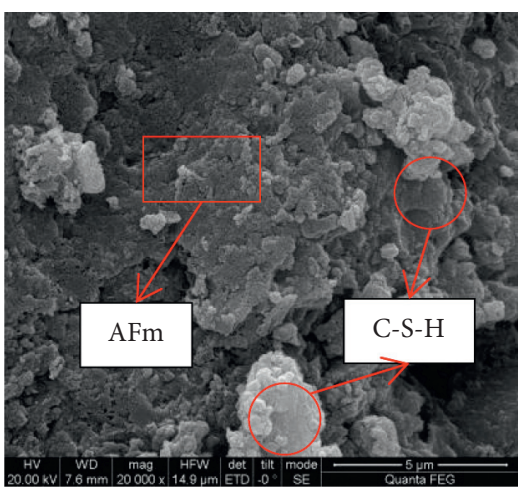

(a)

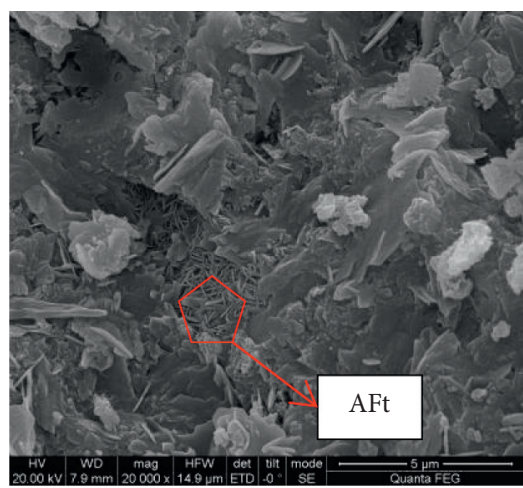

(b)

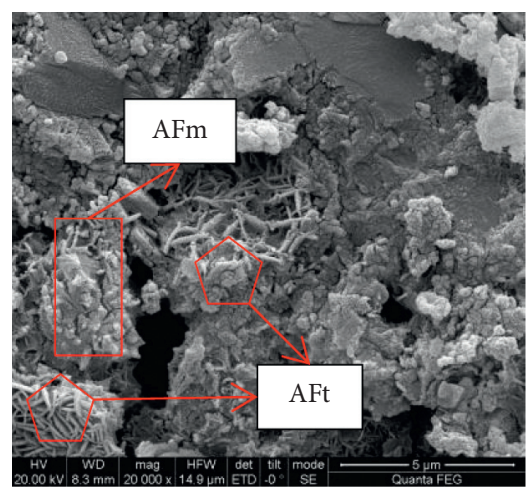

(c)

FIgURE 8: The micromorphology of the new material at different curing ages. (a) Curing for three days, (b) curing for seven days, and (c) curing for sixty days.

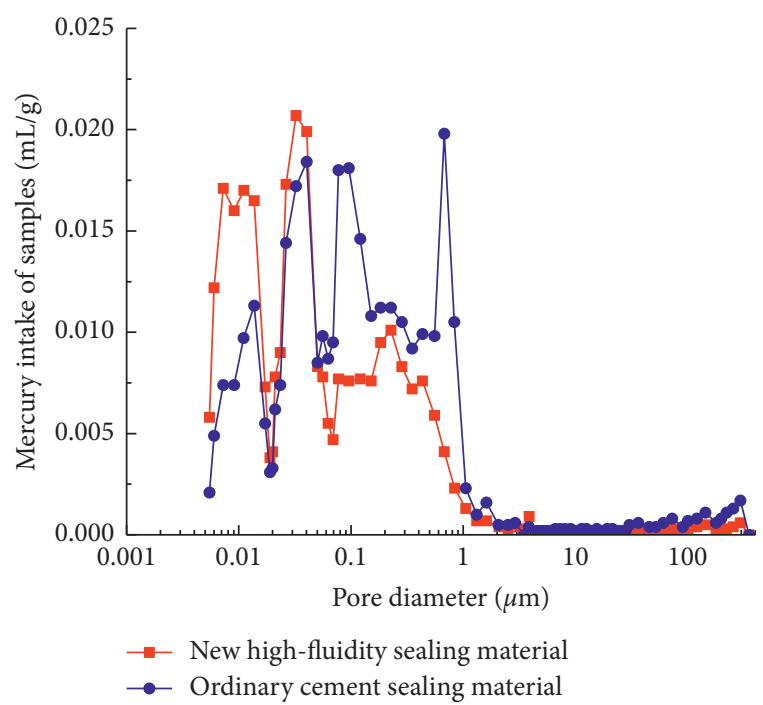

Figure 9: Distribution curves of pores of different sizes in two materials.

$45 \mathrm{kPa}$. After closing the valve for 80 minutes, the gas chamber pressure began to drop. During the whole experiment, the pressure of the gas chamber dropped slowly, and the slope of the curve was small. After closing the valve for 540 minutes, the pressure of the air chamber dropped to $0 \mathrm{kPa}$. The results show that the sealing performance of the new high-fluidity sealing material is better than that of the ordinary cement sealing material under the condition of the same length of the sealing section.

\section{Field Test}

In order to verify the sealing effect of the new high-fluid sealing material and to solve the problem of low gas concentration in the predrainage boreholes of Baode Mine, field tests were carried out in combination with the actual situation of Baode Mine. The original sealing material used in Baode Mine is ordinary cement, which has a poor sealing effect and low gas sampling efficiency.
5.1. Field Situation. Baode Coal Mine is located in Baode County, Xinzhou City, Shanxi Province, and belongs to the Hedong Coalfield. The study area is the return air passage of the 81310 coal mining face in the third panel area of Baode Mine. The coal seam excavated in the working face is the Permian 8\# coal seam. The coal seam is generally approaching the north-south direction and is a wide and gentle west-inclined monoclinic structure. The coal seam is approaching south-north and the coal seam dip is $3^{\circ} \sim 5^{\circ}$, with an average of $4^{\circ}$. The elevation of the coal seam floor in this area is $595-598 \mathrm{~m}$. The thickness of the coal seam is $10.5 \sim 10.8 \mathrm{~m}$. The structure of the coal seam is relatively complicated, with 4-5 layers of gangue. The maximum thickness of a single layer of gangue is $1.05 \mathrm{~m}$. The original gas content of the tunneling face of the return air bypass is about $7.05 \mathrm{~m}^{3} / \mathrm{t}$, and the absolute gas emission is $1.5 \mathrm{~m}^{3} / \mathrm{min}$. The $8 \#$ coal seam belongs to the spontaneous combustion coal seam, the spontaneous combustion tendency grade is II, and the fire period is 105-262 days.

5.2. Borehole Layout and Sealing Method. In the construction of bedding boreholes in No. 81310 return air duct, each hole is designed to be $200 \mathrm{~m}$ in length (Figure 14). According to parameters such as the permeability coefficient of the coal seam in the mine, the influence of certain fissures is considered. In the process of drilling and sealing gas drainage, the sealing method of "bag-type two plugs and one injection" is used; at the sealing position, a sealing length of $0-8 \mathrm{~m}$ is used. Use these two different sealing materials to carry out the sealing test, corresponding to the first group (ordinary cement-based sealing) and the second group (new high-fluidity sealing material), each group of 5 drilling holes. The spacing between each hole is $5 \mathrm{~m}$, and the spacing between each group of drilling holes is $20 \mathrm{~m}$. Monitor the gas concentration and gas scalar data of each group of drilling holes, and detect the sealing effect of the new highfluid sealing material by analyzing and comparing the drilling data.

5.3. Test Results and Discussion. The results of the first and second boreholes were analyzed. According to the test data, the gas concentration diagram (Figure 15(a)) and the 


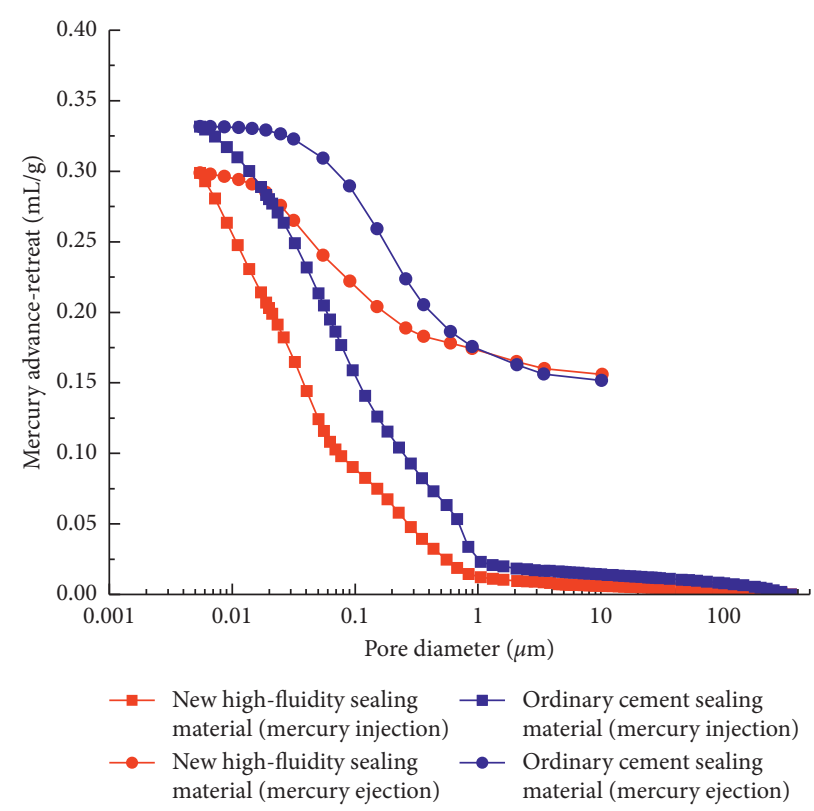

FIGURE 10: Relationship between mercury volume and pore size of different materials.

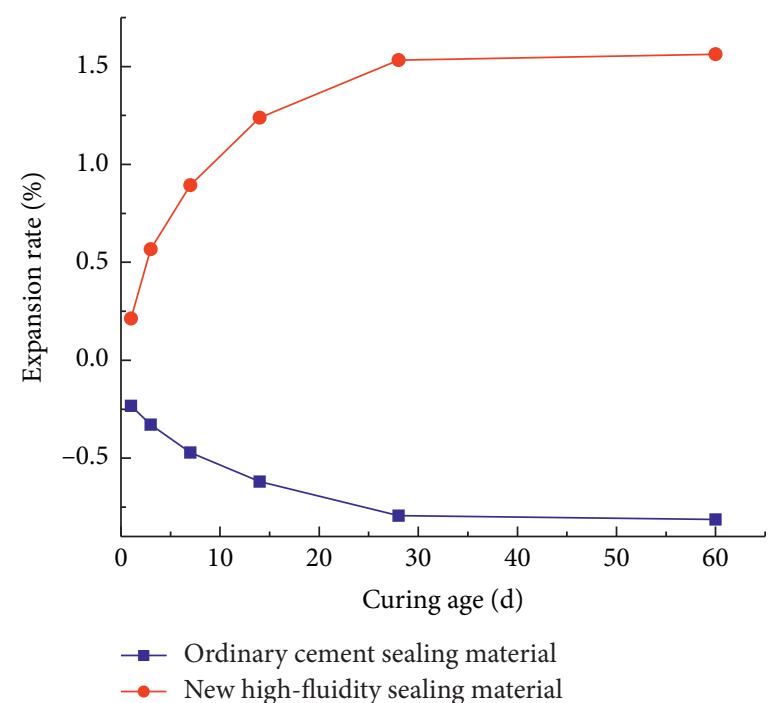

Figure 11: Change rule of expansion rate between new high-fluidity material and common cement material.

drainage flux (Figure 15(b)) over time of the two sets of boreholes were analyzed.

It can be seen from Figure 15(a) that, during the drainage period, the gas concentration of the second group of boreholes is significantly higher than that of the first group of boreholes. The average gas concentration of the first group of boreholes was $39.67 \%$, and the average gas concentration of the second group of boreholes was 59.07\%. After calculation, the gas concentration of the second group of boreholes is 1.49 times that of the first group of boreholes. From the change of gas concentration, we can see that, in the early stage of drainage, the concentration of gas drainage boreholes is low. This is mainly because the amount of AFt crystals generated by the sealing material at the early stage of hydration is small, and the borehole cannot be completely sealed. After 20 days of extraction, as the hydration reaction continues, a large number of ettringite crystals are formed, and the pores are filled with fine needle-shaped ettringite. The expansion performance of the material is increasing, which effectively improves the sealing quality. The gas concentration began to increase and remained at $40 \%$. When the drainage reaches 50 days, the new high-fluidity sealing material continues to hydrate to form $\mathrm{AFm}, \mathrm{CH}$, and so on, the number of C-S-H gels is increasing, and it is densely and uniformly cross-bonded with the gelling substances such as AFt generated in the previous stage. The uniformity and compactness of the material are increased, and the concentration of the gas extracted is increased, up to $85 \%$. It can 


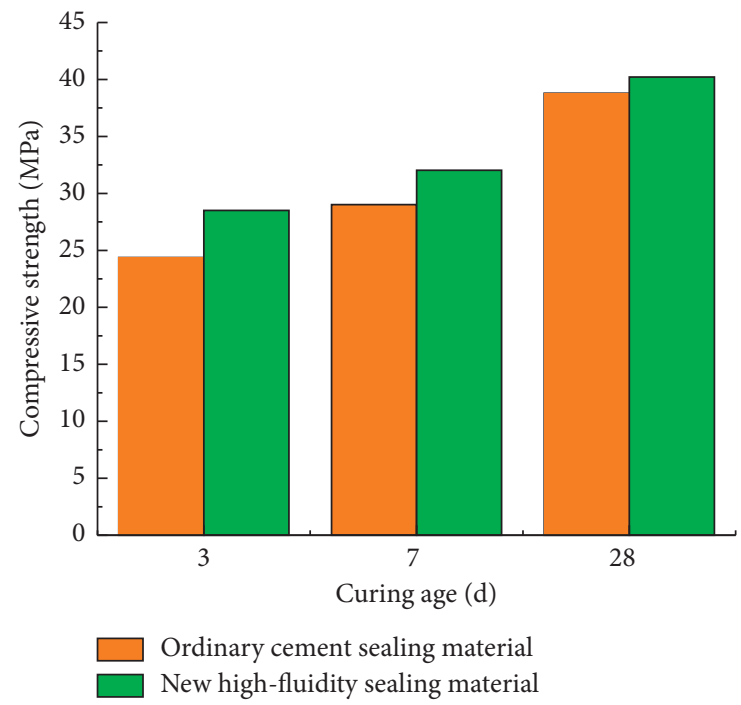

FIGURE 12: Changes in compressive strength of new high-fluidity materials and ordinary cement materials.

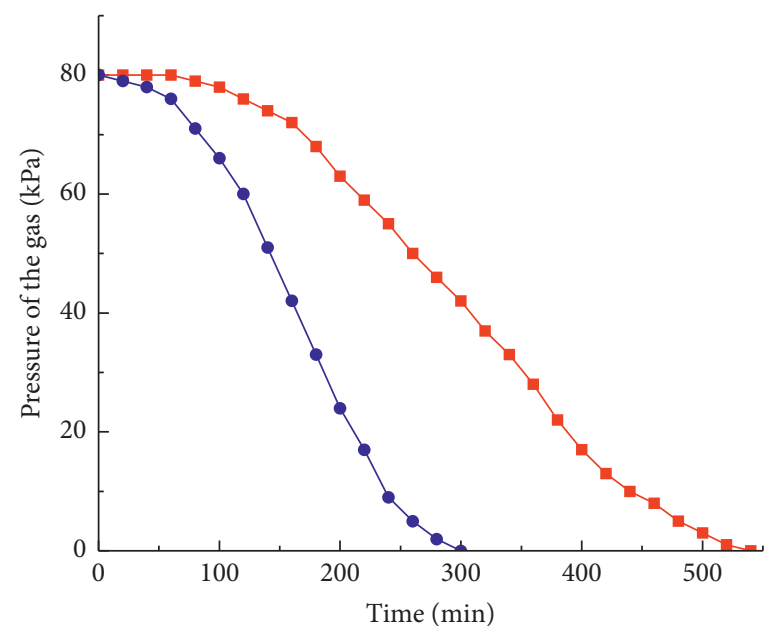

- New high-fluidity sealing material

- Ordinary cement sealing material

FIGURE 13: Air pressure change diagram of different sealing materials.

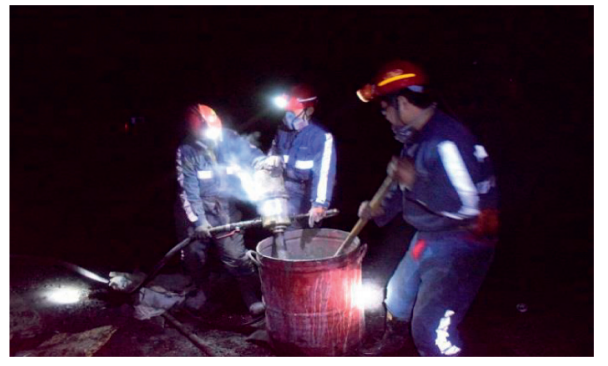

(a)

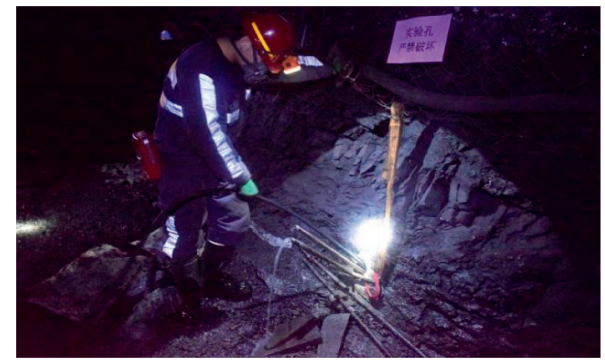

(b)

FIGURE 14: Sealing-grouting diagram. 


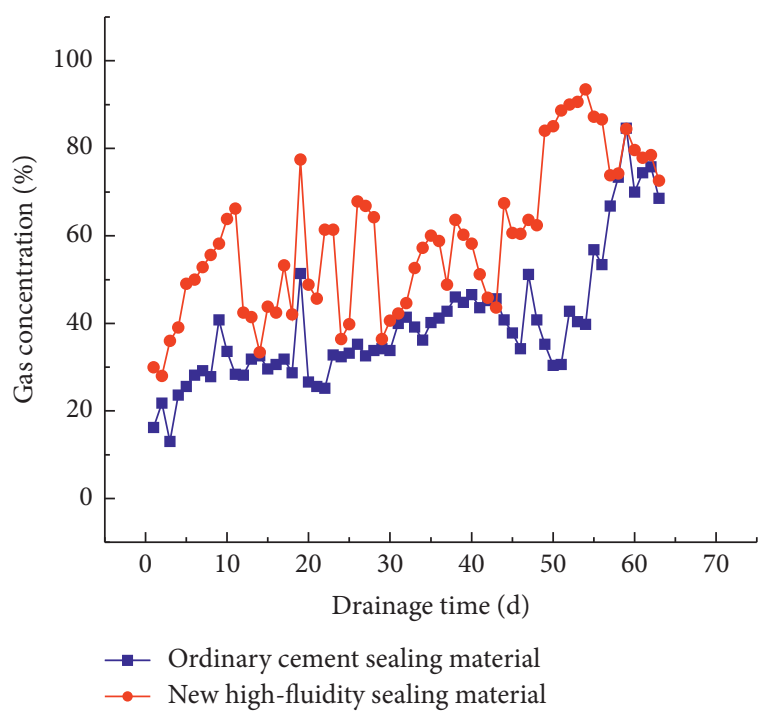

(a)

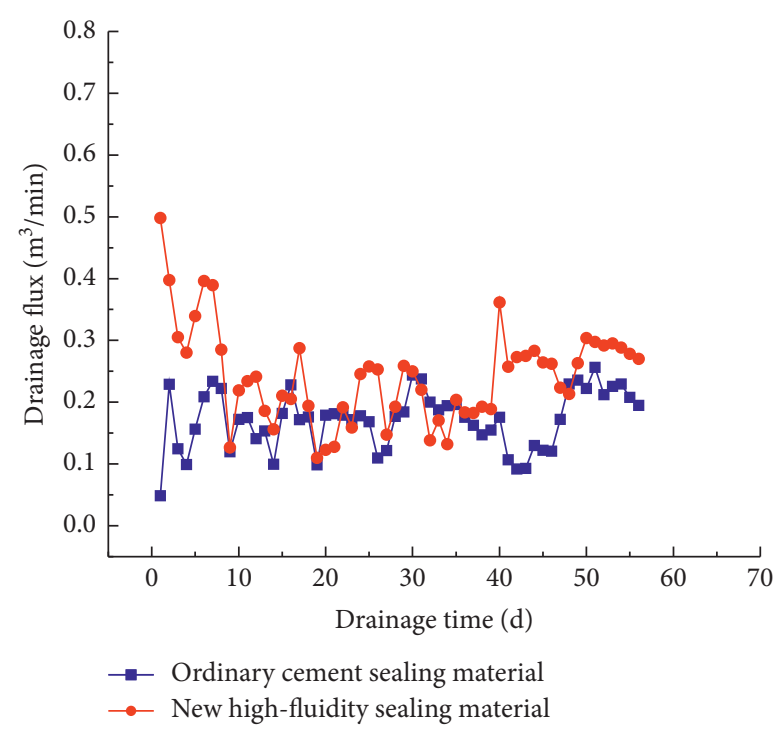

(b)

Figure 15: Two sets of borehole gas concentration and flux with time.

be concluded from Figure 15(b) that, during the drainage period, the drainage flux of the second group of boreholes is significantly higher than the drainage flux of the first group of boreholes. Among them, the drainage flux of the first group of drilling holes is $0.172 \mathrm{~m}^{3} / \mathrm{min}$, and the average drainage flux of the second group of drilling holes is $0.243 \mathrm{~m}^{3} / \mathrm{min}$. The second group of drilling holes is sealed with a new high-fluidity sealing material. The average drainage flux of the holes is $41.28 \%$ higher than that of the first set of drilling holes sealed with ordinary cement materials.

Based on the analysis of the gas concentration and gas purity of the prepumping borehole in Baode Mine 81310 return air channel, it is found that the gas concentration and gas scalar volume of the boreholes sealed with the new highfluidity sealing material are better than the borehole sealed only with ordinary cement materials are high, and the sealing effect is better. Therefore, the new high-fluidity sealing material is suitable for sealing.

\section{Conclusions}

(1) Ultrafine cement with the addition of expansion agent, retarder, and water-reducing agent is developed as a new type of high-fluidity sealing material to meet the performance requirements of fluidity, expansion, compressive strength, and sealing.

(2) The new high-fluidity sealing material is mixed with water to form a stable gel state. The fluidity is $295.5 \mathrm{~mm}$, higher than the fluidity of ordinary cement $(268 \mathrm{~mm})$. After the cement paste is hardened, the expansion rate of the new high-fluidity sealing material is $1.562 \%$, and that of the ordinary cement material is $-0.813 \%$. The compressive strength of the new high-fluidity sealing material at different curing ages is always higher than that of ordinary cement materials. When curing for $3 \mathrm{~d}$, the compressive strengths of the two materials are 24.377 MPa and 28.511 MPa, respectively. When curing for $7 \mathrm{~d}$, the compressive strengths of the two materials are $29.013 \mathrm{MPa}$ and $32.026 \mathrm{MPa}$, respectively. When curing for $28 \mathrm{~d}$, the compressive strengths of these materials are $38.785 \mathrm{MPa}$ and $40.213 \mathrm{MPa}$, respectively.

(3) The microscopic morphology and pore structure tests show that the new high-fluidity sealing material is compact as a whole, and the distribution of micropores is more concentrated. The ordinary cement material has a porous structure as a whole, and the pores are more developed, through which air can flow and the drilling is easy to leak. The overall sealing performance is poor.

(4) The sealing performance test shows that the gas pressure of the ordinary cement material sealing pipe is small, and the pressure decreases fast. The gas pressure of the new high-fluidity sealing material sealing pipe is large, and the air pressure decreases slowly. It is proved that the sealing performance of the new high-fluidity sealing material is better. As the airtightness has reached the requirement of the negative pressure of drainage, the new high-fluidity sealing material has engineering injectability.

(5) The field test results show that, compared with the common cement sealing material, the new high-fluidity sealing material has a good sealing effect. During the experiment, the average concentration of gas extracted from boreholes using the new high-fluid sealing material was maintained above $59.07 \%$, and the average drainage flux of gas extracted reached $0.243 \mathrm{~m}^{3} / \mathrm{min}$. The average gas concentration and flux of the boreholes sealed with ordinary cement materials were only $39.67 \%$ and $0.172 \mathrm{~m}^{3} / \mathrm{min}$. Therefore, the new high-fluidity sealing material significantly improves the efficiency of 
gas drainage and ensures the safe production of coal mines.

\section{Data Availability}

The data used to support the findings of this study are available from the corresponding author upon request.

\section{Conflicts of Interest}

The authors declare that there are no conflicts of interest regarding the publication of this paper.

\section{Acknowledgments}

This research was financially supported by the National Key Research and Development Program of China (2018YFC0808000), National Natural Science Foundation of China (51904013), Youth Science and Technology Talents Support Program (2020) by Anhui Association for Science and Technology (RCTJ202005), and Open Research Fund of State Key Laboratory of Coal Resources and Safe Mining, CUMT (SKLCRSM20KF003).

\section{References}

[1] L. Yuan, "Strategic thinking of simultaneous exploitation of coal and gas in deep mining," Journal of China Coal Society, vol. 41, no. 1, pp. 1-6, 2016.

[2] W. Si, M. L. Cao, and J. Q. Feng, "Advances in research on flowability and rheological properties of fiber reinforced cementitious composites," Materials Reports, vol. 33, no. 3, pp. 819-825, 2019.

[3] M. L. Cao, L. Xu, and Z. W. Li, "Rheology and flowability of polyvinyl alcohol fiber and steel fiber reinforced cement mortar," Journal of Building Materials, vol. 20, no. 1, pp. 112-117, 2017.

[4] C. Zhai, X. W. Xiang, X. Yu et al., "Sealing performance of flexible gel sealing material of gas drainage borehole," Journal of China University of Mining \& Technology, vol. 42, no. 6, pp. 982-988, 2013.

[5] C. Zhai, X. W. Xiang, Q. L. Zou et al., "Influence factors analysis of a flexible gel sealing material for coal-bed methane drainage boreholes," Environmental Earth Sciences, vol. 75, no. 5, Article ID 385, 2016.

[6] X. Xiang, C. Zhai, Y. Yu, and J. Xu, "A flexible gel sealing material and a novel active sealing method for coal-bed methane drainage boreholes," Journal of Natural Gas Science and Engineering, vol. 26, no. 6, pp. 1187-1199, 2015.

[7] Z. M. Wang, Y. N. Sun, W. B. Sun et al., "Study on expansion mechanism and application of double-expansive material for borehole sealing in gas drainage," Journal of Safety Science and Technology, vol. 14, no. 12, pp. 28-33, 2018.

[8] M. Miao, K. W. Xue, F. Miao et al., "Influence of limestone powder on hydration characteristics and rheological properties of cement paste," Journal of Hunan University (Natural Sciences), vol. 45, no. 12, pp. 90-96, 2018.

[9] J. X. Zhang, Y. N. Sun, Z. D. Sun et al., "Analysis of macroscopic mechanical properties and mechanism of coal dust/ polymer composite grouting material," Chinese Journal of Rock Mechanics and Engineering, vol. 38, no. 1, pp. 2889-2897, 2019.
[10] Z. D. Sun, J. X. Zhang, Y. N. Sun et al., "Feasibility of a polymer foaming agent as a grouting material for broken coal masses," Advances in Civil Engineering, vol. 2019, Article ID 9084861, 9 pages, 2019.

[11] Y. Du, X. J. Pei, R. Q. Huang et al., "Study on flow characteristics and application of viscosity time-varying grouting material," Rock and Soil Mechanics, vol. 38, no. 12, pp. 3498-3504, 2017.

[12] M. Kazuki, S. Daiki, K. Hirokatsu et al., "Effect of nonadsorbed superplasticizer molecules on fluidity of cement paste at low water-powder ratio," Cement and Concrete Composites, vol. 97, pp. 218-225, 2019.

[13] H. Güllü, A. Cevik, K. M. A. Al-Ezzi, and M. E. Gülsan, “On the rheology of using geopolymer for grouting: a comparative study with cement-based grout included fly ash and cold bonded fly ash," Construction and Building Materials, vol. 196, pp. 594-610, 2019.

[14] Q. B. Wang, Q. K. Zhu, T. S. Shao et al., "The rheological test and application research of glass fiber cement slurry based on plugging mechanism of dynamic water grouting," Construction and Building Materials, vol. 189, pp. 119-130, 2018.

[15] S. Wang, J. F. Wang, C. P. Yuan et al., "Development of the nanao-composite cement: application in regulating grouting in complex ground conditions," Journal of Mountain Science, vol. 15, no. 7, pp. 119-130, 2018.

[16] S. Kamalakannan, R. Thirunavukkarasu, R. G. Pillai, and M. Santhanam, "Factors affecting the performance characteristics of cementitious grouts for post-tensioning applications," Construction and Building Materials, vol. 180, pp. 681-691, 2018.

[17] R. Bi, W. Cheng, and X. Chen, "Effect of calcium sulfate variety and content on hydration mechanism of grout sealants for coal-bed methane drainage boreholes," Construction and Building Materials, vol. 203, pp. 443-455, 2019.

[18] N. Wongkornchaowalit and V. Lertchirakarn, "Setting time and flowability of accelerated portland cement mixed with polycarboxylate superplasticizer," Journal of Endodontics, vol. 37, no. 3, pp. 387-389, 2011.

[19] S. Mohajerani, A. Baghbanan, G. Wang, and S. F. Forouhandeh, "An efficient algorithm for simulating grout propagation in 2D discrete fracture networks," International Journal of Rock Mechanics and Mining Sciences, vol. 98, pp. 67-77, 2017.

[20] L. Fan, H. M. Zhou, and Y. H. Zhang, "Influence of microfractures on strength parameters of engineering rock mass," Chinese Journal of Rock Mechanics and Engineering, vol. 30, no. 1, pp. 2703-2709, 2011.

[21] Z. Y. Huang, Y. Q. Liu, and C. W. Li, "Performance research of ultra high performance concrete incorporating HCSA expansion agent," Materials Review, vol. 29, no. 4, pp. 116-121, 2015.

[22] B. Li, L. H. Xu, Y. S. Gu et al., "Investigation on influence of HCSA expansive agent on dosage on performance of highstrength self-compacting concrete," Engineering Journal of Wuhan University, vol. 50, no. 1, pp. 90-96, 2017.

[23] J. J. Feng, M. Miao, and P. Y. Yan, "Hydration and expansion properties of shrinkage-compensating composite cementitious materials," Journal of Building Materials, vol. 15, no. 4, pp. 439-445, 2012.

[24] R. R. Du, X. Zhang, M. D. Gu et al., "The composition effect and mechanism of polycarboxylate superplasticizers and early strength agent," Materials Review, vol. 33, no. 14, pp. 24612466, 2019. 
[25] L. Shui, Z. Sun, H. Yang, X. Yang, Y. Ji, and Q. Luo, "Experimental evidence for a possible dispersion mechanism of polycarboxylate-type superplasticisers," Advances in Cement Research, vol. 28, no. 5, pp. 287-297, 2016.

[26] H. C. Du, Y. N. Wang, M. M. He et al., "Study on the effect of organic retarder on the performance of cement modified emulsified asphalt mastic," Materials Review, vol. 33, no. 2, pp. 254-260, 2019.

[27] J. J. Bai, M. Wang, C. J. Shi et al., "Design, synthesis of viscosity-reducing polycarboxylate superplasticizer and its influence on cement-silica fume paste with low water-binder ratio," Materials Review, vol. 34, no. 3, pp. 6172-6179, 2020.

[28] B. Li, "Study on the mechanism of microscopic mechanics of hydrated calcium silicate (C-S-H) gel," Doctor's thesis, Harbin Engineering University, Harbin, China, 2018.

[29] X. Zhang, C. Wu, and S. Liu, "Characteristic analysis and fractal model of the gas-water relative permeability of coal under different confining pressures," Journal of Petroleum Science and Engineering, vol. 159, pp. 488-496, 2017.

[30] H. Guo, L. Yuan, Y. Cheng et al., "Effect of moisture on the desorption and unsteady-state diffusion properties of gas in low-rank coal," Journal of Natural Gas Science and Engineering, vol. 57, pp. 45-51, 2018.

[31] V. A. Mendhe, M. Bannerjee, A. K. Varma, A. D. Kamble, S. Mishra, and B. D. Singh, "Fractal and pore dispositions of coal seams with significance to coalbed methane plays of East Bokaro, Jharkhand, India," Journal of Natural Gas Science and Engineering, vol. 38, pp. 412-433, 2017.

[32] R. R. Xiong, G. C. Long, Y. J. Xie et al., "Influence of mineral admixtures on compressive strength and pore structure of steam-cured high-strength cement paste," Journal of the Chinese Ceramic Society, vol. 45, no. 2, pp. 175-181, 2017. 